INTERNATIONAL ASTRONOMICAL UNION

SYMPOSIUM No. 42

\title{
WHITE DWARFS
}

Edited by W. J. LUYTEN
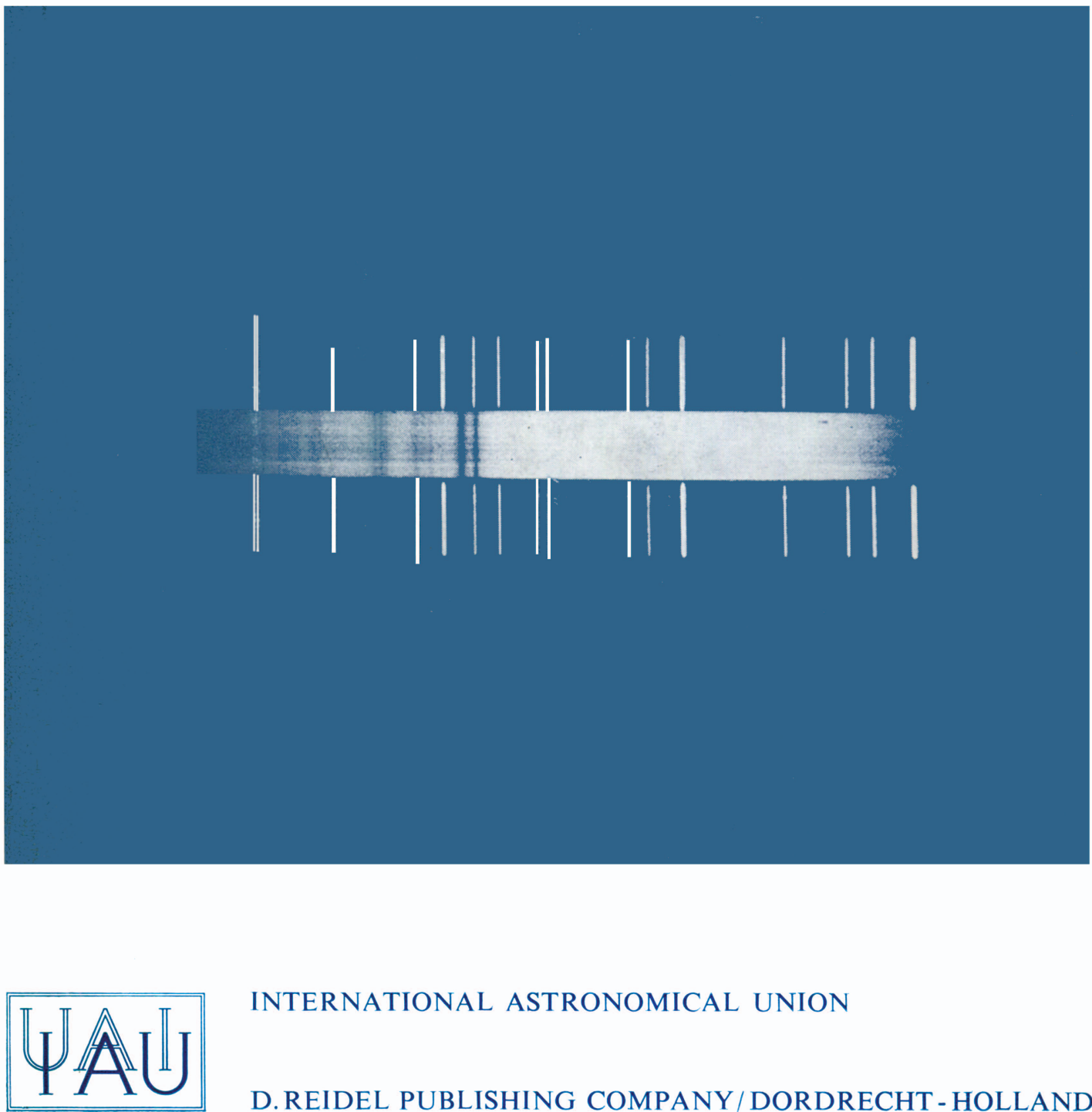

INTERNATIONAL ASTRONOMICAL UNION

D. REIDEL PUBLISHING COMPANY/DORDRECHT - HOLLAND 


\section{WHITE DWARFS}

SYMPOSIUM No. 42

The Proceedings of the First International Conference on White Dwarfs, held from 11-13 August at the University of St. Andrews, brought together, for the first time in this field, twenty-seven astronomers, observational as well as theoretical in roughly equal numbers.

The twenty-five papers presented reflect the same approximate participation. Since the book deals with the first and only conference ever held on the subject, it gives not only a completely up-to-date picture of the observational and theoretical aspects of White Dwarfs, but also describes the entire history of the field from 1918, its beginning, onward. 
WHITE DWARFS 
INTERNATIONAL ASTRONOMICAL UNION UNION ASTRONOMIQUE INTERNATIONALE

\author{
SYMPOSIUM No. 42
}

HELD AT ST. ANDREWS, FIFE, SCOTLAND,

11-13 AUGUST 1970

\title{
WHITE DWARFS
}

EDITED BY

W. J. LUYTEN

University of Minnesota, Minneapolis, Minn., U.S.A.

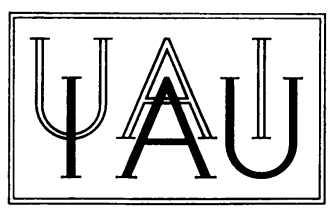

D. REIDEL PUBLISHING COMPANY DORDRECHT-HOLLAND

1971 


$$
\text { Published on behalf of }
$$

the International Astronomical Union

by

D. Reidel Publishing Company, Dordrecht, Holland

\author{
All Rights Reserved
}

Copyright (c) 1971 by the International Astronomical Union

Library of Congress Catalog Card Number 75-146966

ISBN 9027701806

No part of this book may be reproduced in any form, by print, photoprint, microfilm, or any other means, without written permission from the publisher

Printed in The Netherlands by D. Reidel, Dordrecht 


\section{TABLE OF CONTENTS}

Introduction $\quad \mathrm{V}$

Opening Remarks VII

1. W. J. Luyten

The White Dwarfs. Discovery and Observation 1

Red Subluminous Stars $\quad 8$

2. O. J. Eggen

Parallaxes of White Dwarfs

18

3. K. Aa. Strand

4. J. Churms and

Trigonometrical Parallaxes of LB 3303 and

A. D. Thackeray

LB 3459

5. H. L. Giclas

The Identification of White Dwarf Suspects in the Lowell Proper Motion Program 24

6. P. van de Kamp

An Astrometric Study of van Maanen's Star

The White Dwarfs in the Catalogue of Nearby

Stars of 1969

High Frequency Stellar Oscillations. IV: Photo-

8. J. E. Hesser and

B. M. Lasker

electric Monitoring of Southern White Dwarfs

41

New Spectroscopic Results on Subluminous Stars, V 46

9. J. L. Greenstein

Objective Prism Surveys for New White Dwarfs

61

Effective Temperatures of White Dwarfs

11. J. B. Oke and

H. L. Shipman

12. C. R. O’Dell

The Nuclei of Planetary Nebulae as Progenitors of White Dwarfs

The Polarization of Radiation from White Dwarfs 79

J. D. Landstreet

14. V. Weidemann

White Dwarf Atmospheres

Cooling of White Dwarfs

15. H. M. van Horn

The Line Spectra of White Dwarfs

D. T. Wickramasinghe

17. B. Paczyński

On the Origin of White Dwarfs

124

18. I. Bues

Model Atmospheres for Hydrogen-deficient

White Dwarfs

19. K. H. Böhm and

Convection Zones and Coronae of White

J. Cassinelli

Dwarfs

20. A. Baglin

Gravitational Sorting and Overstability in White

Dwarfs

21. G. Vauclair

Models of White Dwarfs, Radial Pulsations

and Vibrational Stability

22. F. Zwicky

Projections into the Future 